\section{OCs and VTE: a practical answer to an old question}

In a recent commentary in this journal, Jürgen Dinger ${ }^{1}$ argued that that "the risk of VTE [venous thromboembolism] attributable to COCs [combined oral contraceptives] is a class effect, primarily dependent on the dose of estrogen" and that the type of progestogen used in the COC probably does not influence this risk. In an editorial in the British Medical Journal that accompanied the publication of the two largest studies to date on this topic, Nick Dunn ${ }^{2}$ concluded: "All of the more recent progestogens, possibly except norgestimate, now seem to be at a disadvantage with regard to VTE".

As VTE is a very rare event, it is unreasonable to expect the answer to the progestogens and VTE question from a randomised controlled trial. We may thus never be able to exclude residual confounding as a possible explanation for the higher VTE rates found with newer progestogens.

Luckily in clinical practice this does not matter much. For COCs, as for any treatment, health professionals should first recommend the safest and most effective treatment, and in the absence of known differences between treatments we should then consider costs.

Most patients requesting a $\mathrm{COC}$ request it solely for contraception. Most of these patients will be perfectly happy with a COC containing a second-generation progestogen, usually levonorgestrel (LNG). Dr Dinger does not question that COCs containing LNG are at least as safe and effective as those containing one of the newer progestogens.

The basket of care offered by sexual health services is constantly changing. More than was the case in the past, we promote subdermal and intrauterine methods and offer sexually transmitted infection (STI) and HIV screening and manage genital tract infection. To afford to do this we have to keep costs as low as possible. Where budgets are finite and probably shrinking, the cost of prescribing COCs containing a newer progestogen instead of LNG can be measured in fewer implants or intrauterine methods inserted and fewer chlamydia or HIV tests undertaken.

This is as good a reason as any to adhere to Faculty Guidance on 'First Prescription of Combined Oral Contraception', which states: "A monophasic COC containing $30 \mu \mathrm{g}$ ethinyl estradiol with norethisterone or levonorgestrel is a suitable first pill (Grade C)"3.

Rudiger Pittrof, MSc, MRCOG

Consultant, Enfield Community Services

Reproductive and Sexual Health (RASH)

London, UK.

E-mail: rudiger.pittrof@enfield.nhs.uk

\section{Ulrike Sauer, MD}

Specialist Registrar, Enfield Community Services, Reproductive and Sexual Health (RASH), London, UK

References

Dinger J. Oral contraceptives and venous thromboembolism: old questions revisited. J Fam Plann Reprod Health Care 2009; 35: 211-213.

Dunn N. Oral contraceptives and venous thromboembolism. BMJ 2009; 339: b3164.

Faculty of Family Planning and Reproductive Health Care Clinical Effectiveness Unit. First Prescription of Combined Oral Contraception. http://www.fsrh.org/ admin/uploads/FirstPrescCombOralContJan06.pdf [Accessed 18 November 2009].

\section{Reply}

To respond to the letter from Drs Pittrof and Sauer, 1 the two articles published in the British Medical Journal 2,3 assessed the risk of venous thromboembolism (VTE) associated with the use of oral contraceptives (OCs), and in particular the role of the type of progestogen. My commentary 4 addressed the methodological strengths and weaknesses of these two studies. It did not seek to make concrete recommendations for the preferential prescribing of certain progestogens or groups thereof. This would also not be possible on the basis of VTE risk, because it is quite conceivable that progestogens do not differ at all or do differ only slightly with respect to VTE risk but could well differ with respect to other risks - for example, of arterial thromboembolic events such as acute myocardial infarction and stroke.

In addition, progestogens are different with regard to a number of pharmacological characteristics, such as anti-androgenic and antimineralocorticoid properties. While manufacturers' sales organisations often strongly emphasise or even overemphasise differences in the pharmacological profiles of progestogens, that does not mean that these differences are negligible in clinical practice.

At a time when it is becoming increasingly difficult to finance health care, cost-conscious use of pharmaceutical products should not be a taboo topic - especially if these products are not paid fo by the patients or users themselves. This applies, for example, to OCs in the UK - in contrast to the vast majority of other countries. Here I would agree with Drs Pittrof and Sauer. However, I am also explicitly in favour of discussing and critically examining safety concerns that are published about certain groups of OCs yet that are of debateable scientific merit - independently of the price tags on these products. Any other position on this matter would be scientifically questionable as well as irresponsible. The debate surrounding second- and third-generation OCs has made us all aware of how easily questions about safety can become a fullfledged 'pill scare' that does not remain focused on a certain group of products but instead leads to an overall drop in OC use. That can, in turn, lead to increased abortion rates, and does a disservice to women who do not wish to become pregnant.

\section{Jürgen Dinger, $\mathrm{MD}, \mathrm{PhD}$}

Director, Berlin Centre for Epidemiology and Health Research, Berlin, Germany.

E-mail:dinger@zeg-berlin.de

\section{References}

Pittrof R, Sauer U. OCs and VTE: a practical answer to an old question [Letter]. J Fam Plann Reprod Health Care 2010; 36: 44

2 Lidegaard $\varnothing$, Løkkegaard E, Svendsen AL, Agger C. Hormonal contraception and risk of venous thromboembolism: national follow-up study. BMJ 2009; 339: b2890

Van Hylckama Vlieg A, Helmerhorst FM, Vandenbrouck JP, Doggen CJM, Rosendaal FR. The venous thrombotic risk of oral contraceptives, effects of oestrogen dose an progestogen type: results of the MEGA case-contro study. BMJ 2009; 339: b2921.

4 Dinger J. Oral contraceptives and venous thromboembolism: a practical answer to an old question. $J$ Fam Plann Reprod Health Care 2009; 35: 211-213.

\section{Drospirenone and VTE}

Following publication in the October 2009 issue of the commentary article regarding the risk of venous thromboembolism (VTE) with combined oral contraceptives (COCs) and subsequent criticisms, we would like to share some information regarding prescribing in Zagreb, Croatia of a recently introduced $\mathrm{COC}$, containing $3 \mathrm{mg}$ drospirenone and $30 \mu \mathrm{g}$ ethinylestradiol (DRSP/EE) (Yasmin ${ }^{\circledR}$ ). We collected data in the city of Zagreb during the period 2004-2008, employing various data sources as follows: data on inpatients from Zagreb; data on the causes of mortality; data on side effects from the Agency for Drugs and Medicinal Products; and data on drug use from Zagreb pharmacies. The total female population under surveillance was approximately 420000 .

In Zagreb, use of COCs in general increased by $31 \%$ between 2004 and 2008. This rising tendency was especially pronounced after 2005 when the combination DRSP/EE was introduced. In 2005, DRSP/EE accounted for $15.4 \%$ of the overall utilisation of $\mathrm{COCs}$, which increased to $57.7 \%$ in 2008, yielding a 4.4-fold increase. Other COCs classified as fixed combinations of progestogens and estrogens showed a decrease in this period. In common with other COCs, in Zagreb $\mathrm{DRSP} / \mathrm{EE}$ is issued on private prescription by pharmacies. COCs are usually prescribed by gynecologists, but may also be prescribed by other specialists.

The number of reported side effects of all drugs of any kind increased by $69.2 \%$ (i.e. from 993 in 2005 to 1680 in 2008). Annual trends in the rate of hospitalisation showed a decline in women of all age groups as well as in those potentially exposed to COCs. Data on the significant increase in the use of DRSP/EE and concurrently very low rates of hospitalisation for VTE, which continue to decline, suggest that there is no correlation between these two parameters.

\section{Marcel Leppée, $\mathrm{MD}, \mathrm{PhD}$}

Specialist in Public Health, Department of

Pharmacoepidemiology, Andrija Stampar Institute of Public Health, Zagreb, Croatia.

E-mail:marcel.leppee@stampar.hr

Mirela Eric, MD, MSc

Plastic Surgeon, Department of Anatomy, School of Medicine, University of Novi Sad, Novi Sad, Serbia

Josip Culig, MD, $\mathrm{PhD}$

Professor, Department of Pharmacoepidemiology, Andrija Stampar Institute of Public Health, Zagreb, Croatia

Reference

Dinger J. Oral contraceptives and venous thromboembolism: old questions revisited. J Fam Plann Reprod Health Care 2009; 35: 211-213.

Filshie clip migration and retention

We wish to advise journal readers about an unusual case of Filshie clip migration and retention inside the uterine cavity that to our knowledge has never been reported before.

A 68-year-old woman, with three previous vaginal births, presented with postmenopausal bleeding for 2 weeks. She underwent a laparoscopic Filshie clip sterilisation 25 years ago and had been menopausal for 16 years. An ultrasound scan suggested an endometrial polyp that was confirmed on hysteroscopy. A closed Filshie clip was seen within the uterine cavity and attached to the polyp by flimsy adhesions. The clip was removed along its longitudinal axis with forceps after dilating the cervical os. The right ostium was not evident except for a small dimple at its expected site. Histology confirmed a benign endometrial polyp.

The clip was lying relatively freely inside the uterine cavity without being expelled. The likely sequence of events could have been a low-grade foreign body inflammatory reaction that resulted in incorporation and subsequent burrowing of the clip through the uterine wall into its cavity. Burrowing and migration through the Fallopian tube is also a possibility and could explain the closure of the right ostium by post-inflammatory adhesions.

Laparoscopic sterilisation with Filshie clip remains a popular method of permanent contraception since its introduction by Marcus Filshie in 1981. It is a safe and effective method, with a failure rate of 1 in $200 . .^{1}$ The $12.7 \mathrm{~mm}$ long and $4 \mathrm{~mm}$ wide titanium clip is lined with silicone rubber and is closed round the Fallopian tube by means of an applicator leading to avascular tubal necrosis. The tube eventually divides and the stumps heal leaving two occluded ends. ${ }^{2}$ The clip usually remains attached to the site of tubal separation and becomes peritonealised. If there is a delay in peritonealisation, the clip may become detached and migrate through tissue planes. This is estimated to occur in 0.6 per 1000 cases. ${ }^{3}$ Dislodged clips are most commonly found within the peritoneal cavity, typically in the Pouch of Douglas or the paracolic gutters. Migration to the urinary bladder, vagina, rectum and into the perineum leading to an ischiorectal abscess has 
been reported. ${ }^{4}$ Extrusion through the anterior abdominal wall is also known. ${ }^{5}$ These migration events have been reported from 10 months to 13 years following application.

There is a small but significant literature describing unusual migration of the tubal clip. It is unclear if the tubal clip within the uterine cavity contributed to the symptoms or formation of the polyp. Although uncommon, women should be informed of the possibility of tubal clip migration. Tubal patency assessment may be required in women during their reproductive years.

\section{Madhuchanda Dey}

Specialist Registrar, Department of Obstetrics and Gynaecology, Singleton Hospital, Swansea, UK.

E-mail:madhuchandadey@doctors.org.uk

\section{Margery Morgan}

Consultant Obstetrician and Gynaecologist,

Department of Obstetrics and Gynaecology,

Singleton Hospital, Swansea, UK

\section{Myriam Bonduelle}

Consultant Obstetrician and Gynaecologist, Department of Obstetrics and Gynaecology, Singleton Hospital, Swansea, UK

\section{References}

Royal College of Obstetricians and Gynaecologists Male and Female Steril based Clinical Guideline No. 4). London, UK: RCOG Press, 2004.

2 Filshie GM, Casey D, Pogmore JR, Dutton AG, symonds EM, Peake AB. The titanium/silicone rubber clip for female sterilisation. Br J Obstet Gynaecol 1981; 88: 655-662.

United States Food and Drug Administration. Advisory Panel Meeting, 26 February 1996.

Dua RS, Dworkin MJ. Extruded Filshie clip presenting as an ischiorectal abscess. Ann R Coll Surg Engl 2007; 89 :

5 Krishnamoorty U, Nysenbaum AM. Spontaneous extrusion of a migrating Filshie clip through the anterior abdominal wall. J Obstet Gynaecol 2004; 24: 328-329.

\section{Advertising sexual health products}

In the UK, the Independent Advisory Group on Sexual Health and HIV advised improvement in public knowledge of contraception and prevention of sexually transmitted infections (STIs) with media coverage. ${ }^{1}$

However, the UK's Medicines Act of $1968^{2}$ prohibits the advertisement of prescription-only medicines (POMs); any advertisements that may lead to the use of a POM; and any advertisements that refer to products that may be used to procure a termination of pregnancy. Condoms and chlamydia testing can be advertised as these do not now constitute POMs. Unfortunately, sexual health 'products' like contraception are POMs, and cannot be advertised.

The Medicines and Healthcare products Regulatory Agency (MHRA) is the government body responsible for the safety and efficacy of medicines in the UK. It ensures that the advertisement of medicinal products is compliant with both European Commission (EC) and UK law. The MHRA is also behind the reclassification initiative supporting the availability of more medicines from the pharmacy [i.e. pharmacy medicines (Ps)]. An example of a categorisation changed from POM to P relevant to sexual health is Levonelle One-Step ${ }^{\circledR}$, made obtainable over the counter in 2001 to facilitate quick access to emergency contraception. Evidence of access improvement from this reclassification is suggested by the $30 \%$ decrease in the number of emergency contraceptive pills issued by National Health Service (NHS) contraceptive clinics since 2001.3
Another example is Clamelle ${ }^{\circledR}$ (azithromycin), now the first oral antibiotic in the UK to be available without a prescription to asymptomatic individuals with a positive chlamydia test and their partners

This year the Committee of Advertising Practice (CAP), which is concerned with regulating advertising in the UK, carried out a review of its code that involved a public consultation. ${ }^{4}$ The outcome of the CAP code review could facilitate the promotion of sexual health services in future.

Some people do not support the advertisement of sexual health services, and there is a small chance the outcome may be different from that anticipated. However, in this regard, one study on direct to consumer advertising (DTCA) of medicinal products ${ }^{5}$ showed:

- It increases consumer awareness

- It motivates consumers to seek additional information from health professionals and other sources

- It aids patient-doctor discussions

- It even motivates the pursuance of lifestyle changes in place of POMs.

In addition, a systematic review of the impact of DTCA from the consumer's perspective concluded that:

- DTCA can facilitate the compliance process with older consumers (in this case, it will be compliance with a contraceptive method)

- It appears to increase the demand for treatments and medicines (hopefully long-acting reversible contraception, in this case).

This evidence suggests that raising awarenes through advertising has the potential to be successful and could help combat the country's teenage pregnancy and sexually transmitted infection rates.

Hannat Akintomide, MBBS, DFSRH

Specialty Doctor, Camden Contraceptive Services, Margaret Pyke Centre, London, UK.

E-mail: hannat.akintomide@camdenpct.nhs.uk

References

Progress and Priorities - Working Together for High Quality Sexual Health. Review of the National Strategy for Sexual Health and HIV, Report of the Independent Advisory Group on Sexual Health \& HIV, July 2008.

2 The Medicines Act 1968. Accessible at The UK Statute Law Database, Office of Public Health Sector Information, Part of the National Archives www.statutelaw.gov.uk [Accessed 13 May 2009]. Part VI, Sections 95 (a), (b) and Part VIII, Section 130 have been Sections 95 (a)

3 NHS Contraceptive Services, England: 2007-08 Bulletin. October 2008. The Health and Social Care Bulletin. October 2008. The Health and Social Care
Information Centre. www.ic.nhs.uk [Accessed 13 May 2009].

4 The CAP Code Review, issued 26 March 2009 closed 19 June 2009. Relevant documents accessible via website: www.cap.org.uk or http://www.cap.org.uk/ CAP-andBCAP-Consultations/Closed-consultations/CAP-CodeReview-consultation.aspx [Accessed 8 October 2009].

Hoek J, Gendall P, Calfee J. Direct-to-consume advertising of prescription medicines in the United States and New Zealand: an analysis of regulatory approaches and cons $197-227$. 6 Harker M, Harker D. Direct-to-consumer advertising of prescriplion medicines: A systematic review of the evidence trom the perspective of the cor

\section{What's in a name?}

In the January 2004 issue of this journal, Toni Belfield criticised the continuing use of the term 'coil' for intrauterine devices (IUDs). ${ }^{1}$ Six years later, as one of the largest distributors of intrauterine contraception in the UK, I share her frustration!

Toni made the point that much of our language has changed over time (e.g. 'automobile' to 'car') and therefore the change from 'coil' to 'IUD' should not be difficult. Unfortunately, I feel she missed one crucial point and that is that we are all intrinsically, linguistically lazy. In fact, all the examples Toni gave of changing terminology proved this, in that all the newer terms had fewer syllables than those they were replacing (e.g. 'longplaying record' to 'CD' or 'album'). In contrast 'coil' has only one syllable, but 'IUD' has three and that, I believe. is why the majority of us still use 'coil' in preference.

'Coil' is a hard, cold, slightly sinister term, reminiscent of reptilian features. My suggested alternative, on the other hand, is monosyllabic, soft, warm, friendly and may even endow the humble IUD with a flirtatious overtone - I suggest that we should call IUDs 'Tees' (or 'Tease'?). The intrauterine system (IUS), of course, would be 'Hormonal Tease'. (Come to think of it, I went out with one of those when I was at college.)

After a few years of colloquial use, I anticipate male pulses racing when they hear the phrase "Tee's ready" but perhaps experiencing slight anxiety at the cautionary "Hurry up, Tee's getting cold". 'Tee dances' would take on a whole new lease of life, not to mention 'Tee parties' and 'Tee for two'....

So that is my New Year Resolution - I shall not use the term 'coil' ever again. It's 'Tee' for me, and I hope all readers of this journal will follow suit. Anyway, anyone for Tee?

\section{Colin G Parker}

Manager, Clinic Sales, Durbin PLC, South

Harrow,UK.E-mail: c.parker@durbin.co.uk

Reference

Belfield T. What we say and how we say it... J Fam Plann Reprod Health Care 2004; 30: 11.

\section{Reply}

This truly is a no-brainer. I recoil at the term "coil" and I definitely wheeze at the term "Tees"! Why do we have such a problem with using correct and accessible sexual health language? Contraceptive methods have evolved hugely over time: we now have safer, more effective methods, but our language around contraception remains archaic, unclear and confusing. Colin Parker suggests we are intrinsically or linguistically lazy, no - just misguided! ${ }^{1}$ Actually what we do is make assumptions about our clients' abilities and understanding; use terminology we have always used and feel comfortable with, and as such never move on! From first- to fourth-generation intrauterine contraception, we have had all shapes and sizes of intrauterine devices (IUDs): rings, spirals, bows, loops, coils, shields and 7s, to the modern framed and frameless copper and hormonal IUDs we have today, which include $\mathrm{T}$ shapes but not exclusively. So why do we still refer to copper IUDs as coils or, even worse, refer to the levonorgestrel IUD as the hormonal coil? Such terminology bears no resemblance to the IUDs we have today. Talk about intrauterine contraception; use the acronym "IUD", as women can and do understand this. But please do not introduce more misleading terminology such as "Tees" - not even as a tease!

Toni Belfield, FRSPH, Hon FFSRH

Specialist in Sexual Health Information, UK.

E-mail:Toni-b@tiscali.co.uk

1 Parker C. What's in a name? [Letter]. J Fam Plann Reprod Health Care 2010; 36: 45 .

\section{LETTERS TO THE EDITOR}

Letters to the Editor are welcome and generally should not exceed 600 words or cite more than five references. For comments on material published in the most recent issue of the Journal, correspondence should be received within 4 weeks of dispatch of that Journal to be in time for inclusion in the next issue. When submitting letters correspondents should include their job title, a maximum of two qualifications and their address(es). A statement on competing interests should also be submitted for all letters. Letters may be submitted to the Editor or the Journal Editorial Office (details on page 1). 